\title{
Erratum to: An Examination of Cesarean and Vaginal Birth Histories Among Hispanic Women Entering Prenatal Care in Two California Counties with Large Immigrant Populations
}

\section{Enrique Gonzalez-Mendez • Catherine Gonzalez-Maddux •} Celeste Hall • Mary Maddux-Gonzalez • Margaret A. Handley

Published online: 18 March 2011

(C) Springer Science+Business Media, LLC 2011

Erratum to: J Immigrant Minority Health

DOI 10.1007/s10903-011-9450-0

The first author's surname was incorrectly spelled as Gonzales-Mendez; the correct spelling is GonzalezMendez.

The online version of the original article can be found under doi:10.1007/s10903-011-9450-0.

E. Gonzalez-Mendez · C. Gonzalez-Maddux Department of Family and Community Medicine,

University of California San Francisco, San Francisco, CA, USA

E. Gonzalez-Mendez

Family Medicine Residency Program, Santa Rosa, CA, USA

C. Hall

Monterey County Health Department, Monterey, CA, USA

M. Maddux-Gonzalez

Sonoma County Health Department, Sonoma, CA, USA

M. A. Handley $(\bowtie)$

Department of Epidemiology and Biostatistics and Center for Vulnerable Populations, University of California San Francisco, San Francisco, CA, USA

e-mail: handleym@medsfgh.ucsf.edu 